University of Northern lowa

UNI ScholarWorks

Faculty Publications

Faculty Work

1976

\title{
The 'Visual World' Program at the University of Northern lowa, U.S.A.
}

Roy R. Behrens

University of Northern lowa

Kenneth Lash

Let us know how access to this document benefits you

Copyright (C1976 The MIT Press

Follow this and additional works at: https://scholarworks.uni.edu/art_facpub

Part of the Art and Design Commons

\section{Recommended Citation}

Behrens, Roy R. and Lash, Kenneth, "The 'Visual World' Program at the University of Northern lowa, U.S.A." (1976). Faculty Publications. 9.

https://scholarworks.uni.edu/art_facpub/9

This Article is brought to you for free and open access by the Faculty Work at UNI ScholarWorks. It has been accepted for inclusion in Faculty Publications by an authorized administrator of UNI ScholarWorks. For more information, please contact scholarworks@uni.edu. 


\title{
THE 'VISUAL WORLD' PROGRAM AT THE UNIVERSITY OF NORTHERN IOWA, U.S.A.
}

\author{
Roy R. Behrens* and Kenneth Lash**
}

\section{Introduction}

Since the 1950's several psychologists have studied the subject of human selective attention $[1,2]$. It has been called the 'cocktail party problem' because a good example of the exercise of selective attention occurs when a large convivial group of people come together and it is still possible for an individual to isolate from the high noise level of conversation what a particular speaker says. Thus, the psychological question is: How do humans select what they consider significant information from the vast amount of information provided to the senses by the external environment? It is known that the amount of information input to the senses by far exceeds the processing capabilities of the brain and, therefore, a means exists to filter from the input what a human considers as essential at any particular moment. In the case of vision, one must ignore most of what can be seen.

Selective attention is clearly important to artists scientists and technologists, for the sense of sight plays a large role in their work. However, the kind of visual information selected and how it is used may differ greatly in these three domains. Readers of Leonardo are acquainted with the discussions of the possible differences presented by various authors.

That there are dangers inherent in selecting information has long been recognized in modern science and methods have been developed to minimize them. Attentional bias masks alternate routes and thereby acts as a block to creativity and innovation. Furthermore, bias limits the response of the public to the output of both artists and scientists, especially when innovative ideas are presented.

While education unavoidably involves a selection of what is to be taught, that is, brought to the attention of students, educators have been criticized for making the selection needlessly narrow. Students are mainly shown routes through cognitive 'tunnels' to the neglect of attentional flexibility or 'switches of salience', the kind of switch of attention that Kierkegaard describes in 'The Rotation Method' [3] in which he filters out a lecture that he found boring and concentrates on

\footnotetext{
* Designer and teacher, Dept. of Art, University of Northern Iowa, Cedar Falls, IA 50613.

** Writer and teacher (same address as above). (Received 19 September 1975.)
}

drops of sweat that hang from the lecturer's nose. This implies that Kirkegaard in making the switch made a better use of the time he spent at the lecture.

The initiation in September 1971 of the 'Visual World' Program for art students was a response to the criticism of education mentioned above. In a report on our Program to the New York State Council on the Arts, it was stated that although the Program is addressed to the university level, it provides the basis on which to build a teaching approach at other levels of education [4]. Currently, I (K.L.), the Program's originator, and Edwin Harris are making a film on the Program with financial support from the University and the Iowa Arts Council.

\section{The 'Visual World' Program}

The essential aim of the program is to develop a demonstrable improvement in the flexibility of art students' selective attention, that is, to train them to notice that which they have visually ignored. This is attempted taking into account the fact that individuals may differ in terms of their modes of cognition, ranging from 'global' perceivers, who have difficulty in distinguishing details of a scene, to 'articulated' perceivers, who tend to distinguish too many of them [5].

Unfortunately, neither the money nor the trained personnel is available to the Program for the verification of a student's improvement in his perception by means of measurements of what might be considered to be relevant parameters for attentional flexibility. Instructors, therefore, have attempted to evaluate the improvement of a student's work on the basis of their personal analyses of the student's practical demonstrations and verbal reports. A selection of the most effective approaches from the many that have been tried under the Program will now be described.

\section{A. John Brown's approach}

An objective of the Program is to develop, through a deepening and redirecting of selective attention, a student's awareness of the large amount of information that can be obtained from a familiar object, most of which is usually ignored. This is done, for example, by means of 'The Lemon Experiment', as developed by John Brown.

A group of 20 students is confronted with a shopping bag containing lemons. The students, 
upon each selecting one are told: 'Look at it, feel it, smell it, take it with you where ever you go, even to bed. Get to know as much as you can about it without marking, cutting or biting it. Bring it with you when we meet again in two days'. When the students reassemble, the lemons are collected into a bag, dumped on a table and the students are asked to find their particular lemon. The students are generally amazed to find that they have no difficulty doing so, not only by sight, but some of them by touch and smell when blindfolded. The experiment develops in the students an awareness of the many differences between things that on cursory examination seem to be identical.

The students then draw 'lemon maps', which depict the idiosyncratic features of a particular lemon. In a 'lemon substitution' exercise the students are asked to apply the lemon form to familiar objects as an introduction to the concept of 'category width' (examples produced have been a 'lemon' dirigible and a 'lemon' toilet bowl). They are given the assignment to produce a 'counterfeit lemon' from any material (sponges, stuffed socks, etc.) to learn about affinities between disparate things.

\section{B. Edwin Harris' approach}

In a lecture with multiple and quick exposure slide projection, Edwin Harris demonstrates that things in the environment can be classified according to their visible structural characteristics. For example, students are shown 'branching' structures (rib structures of a leaf, of a parachute, of a bridge) and layered structures (a deck of cards thrown on a table, stratified clouds, shelves of a hardware store). They are then asked to build or to collect objects that have similar basic structures.

\section{Roy Behrens" approach}

I (R.R.B.) demonstrate the usefulness for invention of 'shifts of emphasis' in perceiving affinities in a random collection of images. The students are provided with a sheet on which are reproduced depictions of objects or parts of objects (Fig. 1) and are asked to combine them on the basis of 'hidden

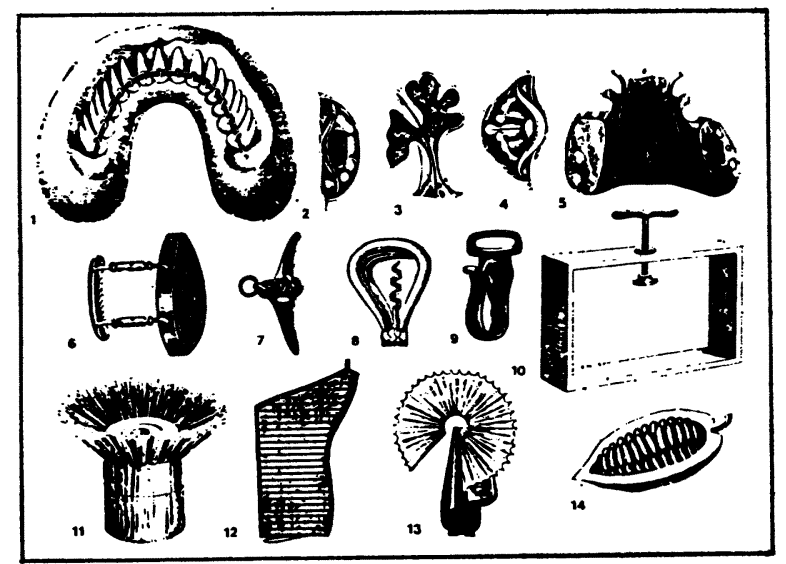

Fig. 1. Depictions of objects to be combined into a recognizable whole. resemblances' into a meaningful whole. A result obtained by a student is shown in Fig. 2. In a second exercise, students are provided with 20 unrelated objects and asked to construct something that makes sound or that can draw.

A third exercise is designed to develop awareness of features of objects that are habitually ignored The students are handed two lists of 15 different objects that are readily obtainable. Each student then selects and obtains one object from each list and is asked to place them into a possible meaningful relationship. For example, a student who has a carrot and a fish bowl may put the carrot in the bowl and call it a goldfish. Next, the students are divided into several groups (say five in each group) and each group is told to arrange their 10 objects in such a way that the arrangement can be interpreted as the plot of a humorous skit. [6].

\section{Frje Echeverria's approach}

In this approach the students are introduced to the idea of 'visual metamorphosis', that is, to transitions from a given image into others that can be derived from it, in order to develop a skill for recognizing resemblances between shapes and forms. Each student is asked to draw quickly a depiction of anything and to give a copy of it to one of his classmates. Each student is directed to 'metamorphose' his original depiction in 20 successive steps on separate sheets of paper into the copy of the depiction he received. The results obtained are then discussed as regards rhythms in a

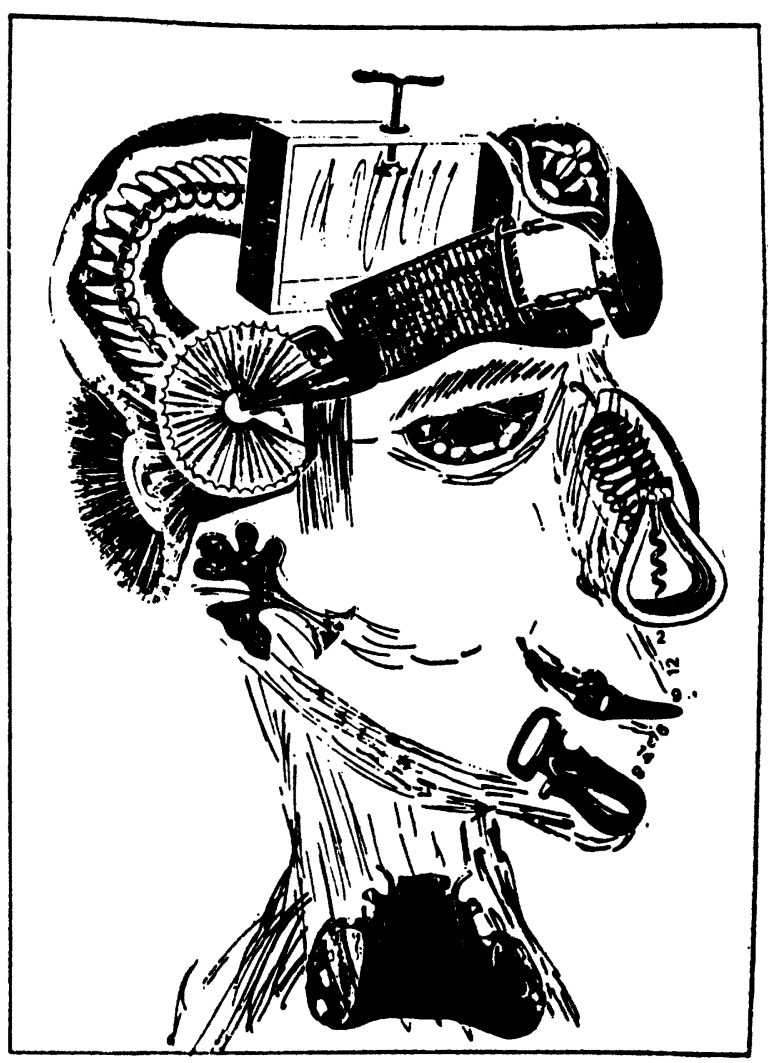

Fig. 2. Example of a student's combination of objects depicted in Fig. 1. 
series of depictions and the effects produced by rearranging their sequence. An animated film is then produced of the various series made by the students.

\section{Concluding remarks}

We believe that the students who have participated in the Program better understand (a) that the selection of information from one's field of vision depends to a great extent on the psychological principle of selective attention, (b) that lack of awareness of the principle is a handicap to those interested in developing or responding to new ideas, (c) that objects perceived as similar may be found to have distinctive differences in appearance and (d) that objects perceived as dissimilar may be found to have common visual characteristics.

Although the Program is designed for art students, we recommend variations of it as an educational method to students in other domains of activity. We would be glad to provide further information on this Program to anyone interested.

\section{References}

1. N. Moray, Listening and Attention (Baltimore: Penguin Books, 1969).

2. G. Reed, The Psychology of Anomalous Experience (Boston: Houghton Mifflin, 1974).

3. R. Bretall, ed., A Kierkegaard Anthology (New York: Modern Library, n.d.) p. 32.

4. K. Lash, Notes toward a New Curriculum in Art, Report of the New York State Council on the Arts, New York, 1971.

5. H. A. Witkin, R. B. Dyk, H. F. Faterson, D. R. Goodenough and S. A. Karp, Psychological Differentiation (New York: Wiley, 1962).

6. R. R. Behrens, On Creativity and Humor: An Analysis of 'Easy Street', J. Creative Behavior 8, 227 (1974). 